\title{
PEMANFAATAN MEDIA SOSIAL OLEH DINAS PARIWISATA \\ DAN KEBUDAYAAN KABUPATEN MALANG DALAM \\ MENINGKATKAN JUMLAH KUNJUNGAN WISATAWAN DI
}

KABUPATEN MALANG

\section{USE OF SOCIAL MEDIA BY THE TOURISM AND CULTURE OFFICE OF MALANG REGENCY TO INCREASE THE NUMBER OF TOURIST VISITS IN MALANG REGENCY}

\author{
Herru Prasetya Widodo ${ }^{1}$, Ardianto ${ }^{2}$ \\ 1,2) Ilmu Komunikasi, FISIP, Universitas Tribhuwana Tunggadewi \\ Email : herru_prasetyawidodo@yahoo.com
}

\begin{abstract}
This study aims to determine how the use of social media by the Department of Tourism and Malang Regency in increasing the number of tourists in Malang Regency and to find out the obstacles in the use of social media by the tourism and cultural department of Malang in increasing the number of tourist visits in Malang Regency. This study uses qualitative research by analyzing the use of social media by the Department of Tourism and Malang Regency. Data collection techniques are carried out on research to obtain data information through interviews and documentation. The results of this study indicate that the use of social media conducted by the Department of Tourism and Culture of Malang Regency is quite helpful in increasing the number of tourist visits in Malang Regency. By paying attention to several factors that affect the effectiveness of the message conveyed through social media, the factor is the content of photos and videos that are interesting, easy to understand and right on target, according to the needs of the audience and provide a suggestion and get responses. The obstacles encountered by the Malang Regency Tourism and Culture Office in utilizing social media to increase the number of tourists coming to Malang Regency are the lack of specialized human resources to fill their social media content. Another obstacle is that sometimes the data obtained from others does not match the facts in the field.
\end{abstract}

Keywords: Utilization, Social Media, Number of Tourist Visits.

\section{ABSTRAK (Times New Roman12, ditebalkan, posisi ditengah)}

Penelitian ini bertujuan untuk mengetahui bagaimana pemanfaatan media sosial oleh Dinas Pariwisata dan Kabupaten Malang dalam meningkatkan jumlah wisatawan di Kabupaten Malang dan untuk mengetahui hambatan dalam penggunaan media sosial oleh dinas pariwisata dan kebudayaan kabupaten malang dalam meningkatkan jumlah kunjungan wisatawan di kabupaten malang.Penelitian ini menggunakan penelitian kualitatif dengan menganalisis tentang pemanfaatan media sosial oleh Dinas Pariwisata dan Kabupaten

ISSN 2338 - 0861 (cetak); e-ISSN 2621 - 8712 (online)

website : http://spektrum.stikosa-aws.ac.id 
Malang Teknik pengumpulan data dilakukan pada penelitian untuk mendapatkan informasi data melalui wawancara dan dokumentasi. Hasil penelitian ini menunjukan bahwa pemanfaatan media sosial yang dilakukan oleh Dinas Pariwisata dan Kebudayaan Kabupaten Malang cukup membantu dalam meningkatkan jumlah kunjungan wisatawan di Kabupaten Malang. Dengan memperhatikan beberapa faktor yang mempengaruhi efektifitas pesan yang disampaikan melalui media sosial, adapun faktor tersebut adalah konten foto dan video yang menarik, mudah dipahami dan tepat sasaran, sesuai dengan kebutuhan yang khalayak inginkan dan memberikan sebuah saran serta mendapatkan tanggapan.Adapun hambatan yang didapatkan Dinas Pariwisata dan Kebudayaan Kabupaten Malang dalam memanfaatkan media sosial untuk meningkatkan jumlah wisatawan yang datang di Kabupaten Malang yaitu kurangnya sumber daya manusia yang khusus mengisi konten media sosial mereka. Hambatan yang lain yaitu, kadang data yang didapatkan dari orang lain tidak sesuai dengan fakta yang ada dilapangan.

Kata-kata Kunci: Pemanfaatan, Media Sosial, Jumlah Kunjungan Wisatawan.

\section{PENDAHULUAN}

Pada zaman modern seperti sekarang ini perkembangan teknologi komunikasi dan informasi sangat berpengaruh dan menjadi bagian yang tidak bisa lepaskan dalam kehidupan sehari-hari.Keberadaan internet sekarang memunculkan interaksi sosial yang berbeda dengan interaksi sebelumnya, dulunya masyarakat berinteraksi dengan bertatapan muka akan tetapi sekarang dimudahkan dengan adanya dunia maya atau melalui internet yang biasa disebut media sosial. Muncul dan berkembangnya internet membawa budaya dan cara komunikasi baru dikalangan masyarakat. Media sosial dibutuhkan untuk merubah perspektif berkomunikasi masyarakat, karena komunikasi bisa terjadi dimana saja dan kapan saja, tanpa harus bertatap muka secara langsung (Tahir \& Dewi, 2019). Media sosial adalah bagian dari bentuk lain media untuk bersosialisasi satu sama lain dan dapat dilakukan secara online serta membuat individu untuk saling berinteraksi tanpa harus dibatasi ruang dan waktu (Wiryohandoyo, 2012:2).
Media sosial merupakan situs yang membantu serta memudahkan individu dapat membuat web page pribadi dan tersanbung dengan individu lain yang tergabung dalam media sosial yang sama untuk berbagi informasi yang dibutuhkan dan melakukan komunikasi (Primasti \& Dewi, 2017). Media sosial juga mampu memberikan dampak yang positif dalam mamasarkan sebuah jasa salah satunya pemasaran obyek wisata daerah. Dilihat dari segi biaya, efektivitas dan kemudahan media sosial cocok sebagai media untuk pengenalan jasa, karena Indonesia merupakan negara yang aktif dalam menggunkan media sosial. Penelitian lain yang dilakukan Widodo pada tahun 2018 yaitu Publisitas merupakan salah satu teknik yang sering digunakan dalam program public relations, karena mampu menjangkau opini publik yang dapat mendukung produk/jasa serta membentuk suatu perceived quality dalam benak konsumen (Widodo \& Yazak, 2018). Dalam hal ini peternak Pak Imam selalu publish dalam group komunitas Facebook maupun viz What' Up dan Blackberry Massenger dalam mempublish produknya sehingga bisa segera menghubungi

ISSN 2338 - 0861 (cetak); e-ISSN 2621 - 8712 (online)

website : http://spektrum.stikosa-aws.ac.id 
jika tertarik barang tersebut karena sudah mendapatkan pelanggan yang loyalitas sehingga tak jarang Pak Imam kewalahan dalam memenuhi keinginan pelanggan jika stock terbatas dan habis dari produknya. Rata-rata pelanggan yang loyalitas ini sudah sangat tahu kualitas dikarenakan kualitas yang bagus serta ada brand yang sudah dibuat oleh Pak Imam dengan nama Sakti dan tercantum nomor handphone pada ring burung lovebirdnya. Sehingga dengan adanya brand pada burung yang dijual telah meningkatkan loyalitas pelanggan karena dengan adanya nama merk pada ring burung.

Hasil penelitian yang pernah dilakukan We Are Social, bahwa perusahaan media asal Inggris yang bekerja sama dengan Hootsuite menunjukkan rata-rata orang Indonesia menghabiskan waktu tiga jam 23 menit sehari untuk dia mengakses media sosial (Jelajahdigital, 2018). Salah satu daerah yang menggunakan media sosial sebagai media penegenalan jasa wisata mereka yaitu Kabupaten Malang.

Sebagai daerah yang memiliki tempat wisata alam yang menarik, Pemerintah Kabupaten Malang memanfaatkan media sosial sebagai alat untuk pengenalan jasa wisata daerah mereka. Lewat media sosial, anda dapat mengatur langkah dan strategi, komunikasi lebih mudah mengalir dibandingkan saat anda berbicara langsung, media pertukaran data dengan menggunakan foto dan video yang di unggah para pengguna internet di seluruh dunia dapat saling bertukar informasi dengan cepat dan murah (Arby dan Dewi, 2017). Media sosial ini dikelola langsung oleh Dinas Pariwisata dan Kebudayaan
Kabupaten Malang. Adapun media sosial yang digunakan oleh Dinas Pariwisata dan Kebudayaan Kabupaten Malang dalam mengenalkan wisata Kabupaten Malang yaitu Facebook, Instagram dan Youtube. Menggunakan nama akun Facebook (Disparbudkabmalang), Instagram (@disparbudkabmalang) dan Youtube (Disparbudkabmalang) Dinas Pariwisata dan Kebudayaan Kabupaten Malang memposting foto dan video tempat wisata yang ada di Kabupaten Malang. Postingan foto dan video di akun media sosial Dinas Pariwisata dan Kabupaten Malang ini akanmembantu memberikan rujukan kepada masyarakat yang ingin berlibur ke Kabupaten Malang.

Dinas Pariwisata dan Kebudayaan Kabupaten Malang cukup aktif dalam penggunaan media sosial untuk mengenalkan wisata Kabupaten Malang. Terbukti dengan banyaknya jumlah wisatawan yang datang berlibur di Kabupaten Malang.Sejak tahun 2015 awal Dinas Pariwisata menggunakan media sosial Instagram jumlah pengungjung wisatawan di Kabupaten Malang hanya 76.663 jiwa kemudian pada tahun 2016 meningkat mencapai 5.849 .544 jiwa dan terus meningkat dari tahun ke tahun hingga pada tahun 2018 jumlah kunjungan wisatawan yang datang ke Kabupaten Malang mencapai 7.172.358 jiwa. Penelitian ini menganalisa secara kualitatif pemanfaatan pesan komunikasi pada media sosial Instagram @disparbudkabmalang selama periode 2015-2018 dalam peningkatan respon masyarakat.

\section{METODE PENELITIAN}

Penelitian ini merupakan penelitian kualitatif deskriptif dengan 
teknik pengumpulan data melalui wawancara dan dokumentasi. Teknik pengumpulan data pada penelitian ini yaitu wawancara informan secara langsung kepada pihak Dinas Pariwisata dan Kebudayaan Kabupaten Malang yaitu Kepala Seksi Analisa Pemasaran Pariwisata Dinas Pariwisata dan Kebudayaan Kabupaten Malang dan Staff Bidang Pemasaran Pariwisata Kabupaten Malang sekaligus admin dari media sosial Dinas Pariwisata dan Kebudayaan Kabupaten Malang. Dokumentasi dalam penelitian ini berupa data tahun 2015 sampai 2018 dari media sosial milik Dinas Pariwisata dan Kebudayaan Kabupaten Malang, data terkait penelitian pada pemberitaan media online, data kunjungan wisatawan. Teknik pengumpulan data dilakukan berdasarkan wawancara dan dokumentasi kemudian data di reduksi dan disajikan sesuai dengan pemanfaatan media sosial yang dilakukan oleh Dinas Pariwisata dan Kebudayaan Kabupaten Malang dalam meningkatkan jumlah kunjungan wisatawan di Kabupaten Malang dan kendala apa saja dalam pemanfaatan media sosial yang dilakukan oleh Dinas Pariwisata dan Kebudayaan Kabupaten Malang dalam meningkatkan jumlah kunjungan wisatawan di Kabupaten Malang. Penarikan kesimpulan berdasarkan hasil wawancara dan data yang diperoleh.

\section{HASIL DAN PEMBAHASAN}

Ada beberapa faktor yang mempengaruhi dalam pemanfaatan media sosial yang digunakan oleh Dinas Pariwisata dan Kebudayaan Kabupaten Malang dalam meningkatkan jumlah kunjungan wisatawan di Kabupaten Malang, adapun faktor tersebut adalah sebagai berikut:

1) Jumlah Followers: Jumlah followers Instagram, dalam menggunakan media sosial Instagram followers adalah hal yang penting, karena followers merupakan orang yang akan melihat setiap unggahan dari akun @disparbudkabmalang. Menurut Nasrullah (2015:21) media sosial merupakan medium yang bekerja berdasarkan informasi, jadi semakin banyak jumlah followers maka akan semakin mudah juga orang mendapatkan informasi tentang wisata di Kabupaten Malang. Menurut Wulandari (2014:95) semakin banyak jumlah followers maka semakin besar pula tingkat loyalitas konsumen. Untuk memperbanyak jumlah followers Dinas Pariwisata Malang mengadakan giveaway untuk menarik perhatian pengguna Instagram agar memfollow akun Instagram @disparbudkabmalang. Hal ini dilakukan oleh Dinas Pariwista dan Kebudayaan Kabupaten Malang karena jumlah followers merupakan hal yang utama dalam memanfaatkan media sosial sebagai wadah memasarkan sebuah jasa wisata. Tanpa followers maka pesan yang disampaikan oleh Dinas Pariwisata dan Kebudayaan Kabupaten tidak akan efektif karena tidak ada komunikan yang menerima pesan tersebut, meskipun pesan tersebut sudah dikonsep dengan baik dan matang.

2) Konten foto dan video yang menarik: dalam hal ini Dinas Pariwisata dan Kabupaten Malang cukup efektif dalam menyampaikan pesan melalui 
unggahan foto dan video wisata yang menarik di akun media sosial Instagram mereka agar dapat menarik perhatian dari pengguna media Instagram . Jika dikaitkan dengan teori efektivitas pesan Wilburn Scramm dalam Hamidi (2015:72) bahwa pesan dikatakan efektif apabila pesan tersebut disampaikan dengan menarik. Pengelola akun Instagram Dinas Pariwisata juga sudah memanfaatkan fitur-fitur yang ada di media sosial Instagram seperti repost foto untuk mendapatkan konten yang menarik, akan tetapi unggahan di media sosial Instagram @disparbudkabmalang masih banyak terlihat unggahan foto tentang kegiatan-kegiatan yang dilakukan oleh Dinas Pariwisata dan Kebudayaan Kabupaten Malang dibandingkan dengan unggahan foto dan video mengenai tempat wisata yang ada di Kabupaten Malang. Hal ini terjadi dikarenakan tidak ada sumber daya manusia yang khusus bekerja mengurus media sosial Dinas Pariwiwsata dan Kebudayaan Kabupaten Malang untuk mencari dan mengisi konten foto dan video tentang wisata yang ada di Kabupaten Malang. Sebaiknya Dinas Pariwisata dan Kebudayaan Kabupaten Malang mencoba mencontoh seperti yang dilakukan oleh pengelola akun Instagram @indotravellers.co yang konsisten dalam mengisi konten mereka dengan hasil me-repost foto dari pengguna media sosial Instagram lainnya. Sehingga akun @disparbudkabmalang bisa memberikan lebih banyak lagi unggahan foto dan video tentang wisata yang ada di Kabupaten
Malang dibandingkan dengan foto kegiatan-kegiatan dan event yang dilakukan di Dinas Pariwisata dan Kebudayaan Kabupaten Malang.

3) Konten yang mudah dipahami dan tepat sasaran: dalam memanfaatkan media sosial Instagram konten foto dan video merupakan pesan yang harus disampaikan kepada khalayak. Komunikator harus bisa mendesain dengan baik pesan yang akan disampaikan agar mudah dipahami komunikan yang melihat isi pesan tersebut. Jika dikaitakn dengan teori efektivitas pesan Wilburn Scramm dalam Hamidi (2015:72) bahwa pesan dikatakatan efektif apabila pesan tersebut harus menggambarkan lambang-lambang yang tertuju pada alamat yang sama antara komunikator dan komunikan sehingga keduanya sama-sama mengerti. Sebagai instansi pemerintah yang menjual jasa destinasi wisata Dinas Pariwisata dan Kebudayaan Kabupaten Malang memperhatikan setiap pesan yang mereka sampaikan melalui foto dan video yang mereka unggah di akun Instagram @disparbudkabmalang. Melalui setiap caption yang mereka tulis secara jelas dan rinci disetiap unggahan foto dan video di akun Instagram @disparbudkabmalang membuktikan Dinas Pariwisata dan Kebudayaan Kabupaten Malang sangat memperhatikan isi pesan yang mereka sampaikan kepada khalayak. Caption yang jelas dan rinci akan mempermudah followers Instagram @disparbudkabmalang untuk mendapatkan informasi yang jelas tentang objek wisata yang mereka 
ingin mereka kunjungi. Karena caption merupakan tulisan yang berfungsi untuk memperjelas makna dari foto dan video yang di unggah oleh akun Instagram @disparbudkabmalang. Pesan yang didesain melalui foto dan video tanpa adanya caption sebagai pendukung untuk memperjelas maksud dari pesan tersebut tidak akan tersampaikan dengan efektif, karena khalayak tidak bisa mengetahui dimana lokasi diambilnya foto dan video tersebut.

4) Konten sesuai dengan kebutuhan: Berlibur menjadi sebuah kebutuhan disela-sela sibuk pekerjaan yang padat. Saat menentukan tempat untuk berwisata tentu setiap orang mempunyai kebutuhan tempat yang berbeda, ada yang suka ke gunung, hutan, pantai dan sebagainya. Semuanya itu tergantung kebutuhan dan bersama siapa mereka akan berwisata, apakah itu bersama teman, pasangan ataupun bersama keluarga. Dari itu Dinas Pariwisata dan Kebudayaan Kabupaten Malang memberikan rekomendasi tempat wisata yang ada di Kabupaten Malang. Melalui akun Instagram @disparbudkabmalang Dinas Pariwisata dan Kebudayaan Kabupaten Malang memberikan gambaran destinasi wisata yang ada di Kabupaten Malang melalui foto dan video yang mereka unggah. Akun Instagram @disparbudkabmalang

mengunggah foto dan video dengan berbagai segmentasi yang berbeda-beda ada foto pantai, air terjun, gunung, hutan dan sebagainya. Hal ini dilakukan oleh
Dinas Pariwisata dan Kebudayaan Kabupaten Malang untuk menyiapkan tempat wisata yang sesuai dengan kebutuhan yang khalayak inginkan. Jika dikaitkan dengan teori efektivitas pesan Wilburn Scramm dalam Hamidi (2015:73) bahwa pesan dikatakan efektif apabila pesan harus membangkitkan kebutuhan pribadi komunikan dan menyarankan beberapa cara untuk memperoleh kebutuhan tersebut. Dalam hal ini Dinas Pariwiwsata dan Kebudayaan Kabupaten Malang mendesain pesan mereka melalui foto dan video dengan bermacam jenis tempat destinasi wisata yang ada di Kabupaten Malang agar sesuai dengan kebutuhan yang khalayak inginkan.

5) Menyarankan sesuatu dan mendapatkan respon atau tanggapan : Saat komunikator menyampaikan sebuah pesan kepada komunikan pasti yang diinginkan dari komunikator tersebut adalah tanggapan atau respon dari komunikan. Karena tanggapan atau respon yang diberikan komunikan adalah tanda bahwa pesan tersebut telah tersampaikan dengan baik. Jika dikaitkan dengan teori efektifitas pesan Wilburn Scramm dalam Hamidi (2015:73) bahwa pesan dikatakan efektif apabila pesan harus menyarankan suatu jalan untuk memperoleh kebutuhan yang layak bagi situasi kelompok dimana komunikan berada pada saat ia disegerakan untuk memberikan tanggapan yang dikehendaki. Melalui akun Instagram @disparbudkabmalang Dinas Pariwisata dan Kebudayaan Kabupaten Malang memberikan 
saran kepada khalayak agar pergi mengunjungi destinasi wisata yang ada di Kabupaten Malang. Saran yang diberikan oleh Dinas Pariwisata dan Kebudayaan Kabupaten Malang dikemas dalam sebuah foto dan video yang menceritakan tentang destinasi wisata yang ada di Kabupaten Malang. Sebuah pesan yang kemas dengan menarik akan mempengaruhi seseorang untuk memberi tanggapan terhadap pesan tersebut. Dalam unggahan Dinas Pariwisata dan Kebudayaan Kabupaten Malang selalu mendapatkan tanggapan dari followers Instagram mereka. Tanggapan atau respon dari khalayak ini menandakan bahwa pesan yang disampaikan oleh Dinas Pariwisata dan Kebudayaan Kabupaten Malang.

Pemanfaatan media sosial ini cukup membantu Dinas Pariwisata dan Kebudayaan Kabupaten Malang dalam meningkatkan jumlah kunjungan wisatawan di Kabupaten Malang. Sejak tahun 2015 Dinas Pariwisata dan Kebudayaan Kabupaten Malang awal menggunakan media sosial Instagram jumlah wisatawan yang datang di Kabupaten Malang mencapai 76.663 jiwa. Akan tetapi setelah satu tahun Dinas Pariwisata dan Kebudayaan Kabupaten Malang aktif menggunakan media sosial Instagram @disparbudkabmalang_jumlah wisatawan yang datang ke Kabupaten Malang mencapai 5.849.544 jiwa dan terus meningkat dari tahun ke tahun hingga pada tahun 2018 jumlah kunjungan wisatawan yang datang ke Kabupaten Malang mencapai 7.172.358 jiwa.
Kenaikan jumlah kunjungan wisatawan ini tidak hanya dipengaruhi oleh media sosial Instagram saja, akan tetapi Dinas Pariwisata dan Kebudayaan Kabupaten Malang juga melakukan promosi melalui media cetak, media elektronik dan melakukan promosi secara langsung ke daerah-daerah didalam negeri maupun ke luar negeri. Akan tetapi media sosial juga mempunyai pengaruh terhadap kenaikan jumlah kunjungan wisatawan yang ada di Kabupaten Malang, karena promosi yang dilakukan melalui media cetak, media elektronik dan promosi secara langsung ini jangkauannya lebih sempit dibandingkan dengan media sosial yang mempunyai kelebihan jangkuannya yang lebih luas dan berdasarkan ciri-cirinya menurut Kaplan dan Michael (2010:10) pesan yang disampaikan melalui media sosial cenderung lebih cepat di banding media lainya.Hal ini membuktikan bahwa media sosial mempunyai pengaruh terhadap peningkatan jumlah kunjungan wisatawan di Kabupaten Malang. Didalam memanfatkan media sosial sebagai media informasi mengenai sebuah wisata tentu ada beberapa hambatan yang dihadapi. Hambatan yang didapatkan oleh Dinas Pariwisata dan Kebudayaan Kabupaten Malang yang pertama yaitu kurangnya sumber daya manusia yang mengurus media sosial di Dinas Pariwisata dan Kebudayaan Kabupaten Malang. Kurangnya sumber daya manusia ini mengakibatkan kurangnya konten yang akan di unggah di akun media sosial Instagram @disparbudkabmalang. Sehingga terjadi kurangnya konten foto dan 
video tentang tempat wisatayang diunggah di akun Instagram @disparbudakabmalang. Kurangnya sumber daya manusia ini juga mengakibatkan terbebengkalainya media sosial Facebook dan Youtube Dinas Pariwisata dan Kebudayaan Kabupaten Malang dan hanya menjalankan media sosial Instagram saja.

Sebaiknya Dinas Pariwisata dan Kebudayaan Kabupaten Malang merekrut orang khusus yang bekerja mengurus media sosial Instagram @disparbudkabmalang dan mengaktifkan media sosial yang lainnya yang telah lama tidak jalan lagi. Karena media sosial mempunyai kekuatan yang besar untuk membantu meningkatkan jumlah wisatawan yang datang di Kabupaten Malang. Dengan media sosial Dinas Pariwisata dan Kebudayaan Kabupaten Malang bisa memasarkan dan memberikan informasi tentang tempat wisata mereka secara cepat dan bisa menjangkau orang banyak. Penggunaan media sosial sebagai alat untuk memasarkan atau memberikan informasi tentang tempat wisata Kabupaten Malang juga tidak butuh menggunakan banyak biaya yang harus dikeluarkan, hanya cukup dengan satu postingan foto atau video saja orang sudah bisa melihat apa yang ingin kita jual. Media sosial juga bisa dengan cepat tersebar dengan luas. Dengan menggunakan bantuan satu media sosial saja peningkatan jumlah kunjungan wisatawan yang datang di Kabupaten Malang sudah mencapai tujuh jutaan pengunjung. Apalagi Dinas Pariwisata dan Kebudayaan Kabupaten Malang mengaktifkan kembali media sosial mereka yang lain mungkin jumlah kunjungan wisatawan bisa mencapai puluhan juta pengunjung. Hal ini bisa terjadi asalkan Dinas Pariwisata dan Kebudayaan Kabupaten Malang secara konsisten dalam mengunggah foto dan video tentang tempat wisata Kabupaten Malang di media sosial yang mereka gunakan.

Hambatan yang kedua yaitu data foto dan video yang didapatkan dari orang lain kadang tidak sesuai dengan fakta yang ada. Hal ini bisa terjadi karena hal utama yaitu kurangnya sumber daya manusia yang mengurus tentang media sosial Dinas Pariwisata dan Kebudayaan Kabupaten Malang. Data yang tidak sesuai dengan fakta dilapangan ini akan memicu kesalah fahaman antara Dinas Pariwisata dan Kebudayaan Kabupaten Malang sebagai komunikator dengan komunikan yang melihat foto dan video yang diunggah oleh akun Instagram @disparbudkabmalang. Unggahan foto dan video yang tidak sesuai dengan fakta ini akan mengakibatkan komplen dari wisatawan yang datang ke destinasi wisata di Kabupaten Malang. Sehingga akan mengakibatkan masyarakat tidak mempercayai lagi unggahan foto dan video akun Instagram @disparbudkabmalang. Dari itu Dinas Pariwisata dan Kebudayaan Kabupaten Malang harus benar-benar memperhatikan setiap foto dan video yang mereka unggah di akun Instagram @disparbudkabmalang, agar tidak terjadinya kesalah fahaman antara Dinas Pariwisata dan Kebudayaan Kabupaten Malang dan khalayak. 


\section{KESIMPULAN}

Hasil analisa dari penelitian ini menunjukkan ada hubungan yang cukup tinggi dari 5 faktor analisa konten media sosial Instagram @disparbudkabmalang. Faktor jumlah follower (5843 orang), faktor jumlah konten video maupun foto berikut faktor pesan-pesan yang menarik sebanyak 1056 postingan memberikan respon yang cukup positif untuk khalayak di dunia digital (media sosial). Respon positif di media sosial ini memberikan efek peningkatan jumlah kunjungan secara fisik pada tempat-tempat wisata di Kabupaten Malang.

Berdasarkan uraian yang telah dipaparkan maka dapat disimpulkan bahwa pemanfaatan media sosial Instagram yang dilakukan oleh Dinas Pariwisata dan Kebudayaan Kabupaten Malang cukup mampu membantu meningkatkan jumlah kunjungan wisatawan yang datang ke Kabupaten Malang. Dengan memperhatikan beberapa faktor yang mempengaruhi efektiftas pesan yang disampaikan melalui media sosial Instagram @disparbudkabmalang. Adapun faktor tersebut adalah konten foto dan video yang menarik, mudah dipahami dan tepat sasaran, sesuai dengan kebutuhan yang khalayak inginkan dan memberikan sebuah saran serta mendapatkan tanggapan yang baik.

Dalam memanfaatkan media sosial sebagai wadah untuk penyebaran informasi sebuah wisata tentu mempunyai beberapa hambatan. Adapun hambatan yang didapatkan Dinas Pariwisata dan Kebudayaan Kabupaten Malang dalam memanfaatkan media sosial untuk meningkatkan jumlah wisatawan yang datang di Kabupaten Malang yaitu kurangnya sumber daya manusia yang khusus mengisi konten media sosial mereka. Sehingga mengakibatkan media sosial yang mereka gunakan ada yang tidak terurus lagi sehingga mereka hanya menggunakan media sosial Instagram saja. Selain itu hambatan yang lain yaitu, kadang data yang didapatkan dari orang lain tidak sesuai dengan fakta yang ada dilapangan.

\section{DAFTAR PUSTAKA}

Arby, Fakhris \& Dewi, Sulih Indra. (2017). Pengaruh Media Sosial Instagram Terhadap Minat Fotografi Pada Komunitas Fotografi Kamera Indonesia Malang, JISIP, Vol 6 No. 2, Hal 6974.

Hamidi. (2007). Metode Penelitian dan Teori Komunikasi. Malang: UMM Press.

Jelajahdigital.com. (2018). Data dan Fakta Istagram dalam Statistik. https://jelajahdigital.com/datadan-fakta-Instagram -dalamstatistik/. Diakses pada tanggal 06 April 2019.

Kaplan, M. and Michael H. (2010). "Users of the World, Unite. The Challenges and Opportunities of Social Media". Business Horizons.

Nasrullah, Rulli. (2015). Media Sosial Perspektif Komunikasi, Budaya dan Sosioteknologi. Bandung. Simbiosa Rekatama Media.

Primasti, Dinar \& Dewi, Sulih Indra. (2017). Pengaruh Media Sosial Terhadap Penyimpangan Perilaku Remaja (Cyberbullying). Jurnal Reformasi Volume 7 No. 2 (2017) hal $34-43$

Satvikadewi, A. A. I., \& Kusumaningrum, H. (2019). Profil Psikografis \& Penggunaan Media 


\begin{tabular}{lr} 
pada Kelompok & Milenial \\
Pengunjung Kebun & Binatang \\
Surabaya. Jurnal & Spektrum \\
Komunikasi, $7(2)$, & $15-28$. \\
https://doi.org/10.37826/spektr \\
\hline um.v7i2.32
\end{tabular}

Tahir, Husen Bin. dan Dewi, Sulih Indra. (2019). Eksploitasi Perempuan Dalam Aplikasi Bigo Live Ditinjau Dari Perspektif Feminisme Marxis-Sosialis. Jurnal JISIP Volume 8 No. 1 (2019) hal 35 $-45$

Wicaksono, Dedy A. (2018). Efek Strategi Komunikasi Pemasaran pada Loyalitas Pelanggan Apotek K-24 Mulyosari. Jurnal Spektrum Komunikasi, 6(2), 28-33. https://doi.org/10.37826/spektr um.v6i2.41

Widodo, Herru Prasetya \& Yazak, Ellen Meianzi. (2018). Strategi Komunikasi Pemasaran Peternak Lovebird Dalam Meningkatkan Loyalitas Pelanggan Jurnal Volume 8 Nomor 1 (2018) hal 1-7

Wiryohandoyo, S. (2012). Perubahan Sosial dalam Masyarakat Modern. Yogyakarta: Tiara Wacana. 